\title{
Limites e potencialidades da participação: na experiência do Programa Descentralização da Cultura de Porto Alegre
}

\author{
Gabriela Cordioli Coto
}

Universidade Federal da Santa Catarina. Florianópolis, SC.

Email: gabriela.ccoto@gmail.com

\section{Cristina Amélia Carvalho}

Universidade Federal do Rio Grande do Sul. Porto Alegre, RS.

Email: cris_carvalho@uol.com.br

Resumo: O Programa Descentralização da Cultura, da Secretaria Municipal de Cultura de Porto Alegre, é resultado de uma luta travada por grupos da sociedade civil nos anos 80 e 90, que objetivavam qualificar a participação no âmbito da gestão municipal e modificar os rumos das políticas culturais municipais. O presente artigo, buscou resgatar a experiência do Programa Descentralização de Cultura de Porto Alegre e sua contribuição para a radicalização democrática e formação de novos valores e práticas sociais, pautadas pela ética coletiva. política.

Palavras-chave: Cultura; políticas culturais; descentralização; participação

\section{Límites y potencial de participación: la experiencia de Descentralización del Programa de Cultura en Porto Alegre}

Resumen: El Programa de Descentralización de la Cultura de la Secretaría Municipal de Cultura de Porto Alegre, es resultado de una lucha trabada por grupos de la sociedad civil en los años 80 y 90, que tuvieron por objetivo cualificar la participación en el ámbito de la gestión municipal y modificar el rumbo de las políticas culturales municipales. Este artículo, buscó rescatar la experiencia del Programa de Descentralización de la Cultura de Porto Alegre y su contribución para la radicalización democrática y formación de nuevos valores y prácticas sociales, gobernadas por la ética colectiva. ción política.

Palabras clave: Cultura, políticas culturales, descentralización, participa-

\section{Limits and participation potentiality: the experience of the Decentralization of the Cultural Program in Porto Alegre}

Abstract: The Decentralization of the Cultural Program of the Secretary 
of Culture of the Municipality in Porto Alegre, is the result of a struggle carried out by civil society groups in the ' 80 s and ' 90 s, which aimed to qualify the participation in municipal management and to change the path of municipal cultural policies. This article sought to rescue the experience of the Program of Cultural Decentralization of Porto Alegre and its contribution to the democratic radicalization and the adoption of new values and social practices, guided by colective ethics.

Key words: Culture; cultural policies; descentralization; political participation.

\section{Introdução}

O processo de redemocratização que se iniciou nos anos 80 no Brasil, foi marcado por um contexto de pressão social por parte da sociedade civil, que reivindicava abertura política capaz de redefinir as condições políticas concretas no país. Emoldurado por este processo, em 1988 o Congresso Nacional elaborou uma nova constituição que estabelecia a descentralização dos poderes do Estado e a participação da sociedade civil nas decisões políticas, como eixos centrais da gestão pública. Estas determinações visavam possibilitar a inclusão novos atores no cenário político e obter maior sustentabilidade e legitimidade, o que auxiliaria no processo de desenvolvimento social.

Neste contexto, o tema da participação tornava-se elemento central nos debates políticos. Coube nessa altura ao Partido dos Trabalhadores (PT), nascido em 1980 mas gestado na década anterior a partir das lutas do movimento sindical e da ação dos setores mais progressistas da Igreja Católica, incorporar mais eficazmente o elemento da participação em seu discurso político. Nessa mesma década o PT conquistava alguns governos municipais em localidades nas quais os movimentos sociais eram atuantes, entre eles Piracicaba, São Paulo, Santos, Jaboticabal e Santo André no estado de São Paulo, Ipatinga e Betim em Minas gerais e, Porto Alegre no Rio Grande do Sul.

Estes governos tornaram-se espaços privilegiados para experimentação de arranjos sociais democráticos para a construção de uma legitimidade social necessária para a disputa do governo federal. Uma das bases para a construção do discurso participativo legitimador foi Porto Alegre do qual foi peça chave, no final da década de 80, o Orçamento Participativo (OP). Este se caracterizava como um processo pelo qual a população, através da eleição de representantes, opinava e decidia as prioridades políticas do gasto público para sua região, de uma parte percentual do orçamento municipal.

Da parte do poder público, este processo foi apoiado por uma reforma político-administrativa da cidade, por meio da qual foram criados centros administrativos em 17 regiões da cidade que serviam de espaços de dialogo mais próximos entre poder público e sociedade civil. 
Em 1994, em parte fruto deste processo de aproximação para o dialogo, da qualificação da participação popular mas, principalmente, como desejamos mostrar, da luta pela radicalização democrática empreendida por grupos culturais locais, é criado o programa municipal Descentralização da Cultura de Porto Alegre (DCP/POA). A proposta do Programa, em oposição às primeiras ações da Secretaria Municipal de Cultura que visavam à desconcentração cultural, pautou-se pelos parâmetros dos coletivos da sociedade civil, que pressionavam o poder público pela criação de espaços de discussão e participação social qualificada. A descentralização e participação políticas reivindicadas por estes grupos suplantavam a simples desconcentração cultural do centro da cidade, mas defendiam a descentralização do poder de decisão acerca das políticas culturais. O eixo central de trabalho do Programa eram as oficinas artísticas que, de acordo com a programação oficial, visavam, através de um processo de discussão e conscientização, formar cidadãos ativos e qualificar a participação das comunidades.

A participação qualificada exige, dos atores envolvidos, habilidades políticas e cognitivas que são também forjadas na experiência adquirida na vivencia dos processos de participação. É assim que as oficinas são pensadas como loci de discussão e conscientização política, para as quais o Programa fornecia suporte financeiro e estrutural para além de continuar a apoiar festas e eventos comunitários. Comissões regionais são criadas como espaços administrativos para a experimentação das demandas e políticas culturais de cada região.

Entretanto, a problematização exercitada vai buscar em Nogueira (2004) a afirmação de que os espaços de participação abertos na gestão pública, neste período, foram, em grande parte, utilizados para manter a estabilidade política, estabelecendo mecanismos de cooptação dos movimentos sociais ao invés de uma efetiva democratização. Dependendo das características desta participação e de seus espaçosde exercício, este processo pode harmonizar os atores envolvidos, voltados ao auxílio e cooperação com a gestão pública, rompendo assim sua postura emancipadora, o que diminuiria a possibilidade de mudança efetiva, ao suavizar a participação para a não-intromissão nas escolhas essenciais. Os indivíduos só podem realizar a aprendizagem política e recuperar seu poder social no âmbito da sociedade e de suas organizações, afirma Tragtenberg (1980), e é na experiência de participar em associações, conselhos, fóruns e espaços da administração pública que amplia e qualifica os sujeitos para a criação de valores de coletividade importantes neste processo, segundo Motta (2003).

Diante deste panorama, nossa problematização gira em torno do real potencial de radicalização democrática destes espaços de participação, criados por meio do programa Descentralização da Cultura de Porto Alegre, na gestão pública municipal. Com o intuito de iluminar este debate construímos e apresentamos um retrospecto do DCP/POA e dos movimentos do campo da cultura e que foram determinantes para a sua construção desde 1990 até 
o inicio de 2012. Neste período de tempo, que abarca quatro gestões consecutivas na Prefeitura Municipal de Porto Alegre do PT (1989 1993; 1993 1997; 1997 2001; 2001 2005) e duas do PMDB (Partido do Movimento Democrático Brasileiro) (2005 2009; 2007 2012/1), buscamos identificar, a partir de conceitos e categorias de análise delimitadas mais adiante, momentos de participação efetivamente política (Nogueira, 2004), mas também processos de perda de radicalidade no percurso do Programa.

\section{Estado e sociedade civil}

Compreender o que caracteriza um processo de radicalização democrática passa por uma discussão das concepções e relações entre Estado e sociedade civil, bem como conceitos e relações entre democracia e participação.

O conceito de Estado enquanto organização social, política e jurídica de um território, e que possui a responsabilidade de administrar os interesses da coletividade, foi contestado por Marx (2005) para o qual o Estado expressa, em suas atividades, particularidades e nas relações com a sociedade civil, o conflito de classes. Neste sentido, mais que um fim em si mesmo, o Estado (poder político) é uma relação de dominação de classe mediada pela burocracia com o objetivo de manter e reproduzir as relações de produção às quais ele está submetido (Viana, 2003: 9). e explica:

Em sua crítica a concepção de Estado moderna, Marx (2005) ironiza

O Estado [...] em sua teoria é uma beleza sem par e garantia certa para consecução da justiça neste mundo [...] Os Estados realmente existentes pouco ou nada têm a ver com o que surge de suas disposições teóricas [...] os Estados operam de outro modo, ou seja, os que subordinam a conquista dos interesses universais à satisfação dos interesses particulares de certos grupos e classes sociais, não são verdadeiros Estados, mas simples sociedades civis disfarçadas de Estados. Creia-me quando afirmo que lamento ter que lhe informar que todos os Estados conhecidos demonstram uma irresistível vocação para se disfarçar... Uma vez comprovado o caráter irremissivelmente classista dos Estados e certificada a invalidação do modelo hegeliano do Estado ético representante do interesse universal da sociedade [...] (Marx, 2005: 116).

Com o desenvolvimento das forças e relações de produção, marcadas pela divisão social do trabalho, e o crescente antagonismo entre as classes, foi necessário aumentar o domínio sobre a classe dominada, para que, deste modo, fosse assegurada e mantida a reprodução das relações de produção. Nesta perspectiva, todo Estado é um instrumento de dominação e opressão de classe, expressando sua inseparabilidade dos modos de produção (Viana, 2003). 
O Estado compreende dialeticamente, dois segmentos que são, ao mesmo tempo, distintos e vinculados, defende Gramsci (1999). A sociedade política responsável pela gestão do espaço público, que compreende os aparelhos de coerção sob o controle das burocracias executivas e policialmilitar, e a sociedade civil que engloba o conjunto de organizações responsáveis pela elaboração e/ou difusão e luta contra a dominação e compreende o sistema escolar, as igrejas, os partidos políticos, os sindicatos, os meios de comunicação, etc.

A dominação, mediante a coerção, é exercida pela sociedade política, enquanto no meio da sociedade civil, as classes dominantes buscam aliados para conquistar e manter o consenso social e político, bem como as relações hegemônicas (Domingues, 2009). Neste sentido o Estado é uma arena de força e consenso que, apesar de estar a serviço das classes dominantes, não se mantêm apenas pela força e pela coerção legal. Sua dominação é bem mais sutil e eficaz, realizada pelos meios de comunicação de massa, escolas, igrejas, etc. que, aliadas das classes dominantes na construção de consensos, coadjuvam para manutenção das relações hegemônicas.

Entretanto, como apontou Gramsci (1999), quanto mais a sociedade civil é consciente, politizada e articulada na construção de uma contra hegemonia, maior a resistência à dominação e mais as práticas sociais podem ser modificadas, sendo assim determinadas pela vontade coletiva. Como ressalta Moraes (2002), a hegemonia não representa dominação de uma classe e submissão de outra. Ao contrário, ela incorporava a luta de classes subalternas, que, através da politização, podem desenvolver ações contra hegemônicas. As contradições, a luta de classe, o choque de interesses funcionam como motores da aprendizagem política, ou seja, sendo um espaço político de antagonismo e contradição, a sociedade civil ao se vincular ao espaço público (Estado) funciona como locus de disputa pela hegemonia bem como de luta contra a dominação.

É no âmbito do projeto democrático que se põe efetivamente a questão da sociedade civil, pois fora daí, ela tem um sentido estreito e limitado. Isso quer dizer que, para que se resgate a essência da democracia, é preciso de uma perspectiva que não só valorize a sociedade civil e celebre seu crescente protagonismo, mas também colabore para politizá-la, libertando-a das amarras reducionistas dos interesses particulares, aproximando-a do universo mais rico e generoso dos interesses gerais, da hegemonia, em uma palavra, do Estado (Ibid, 2004). Referimo-nos a um processo no qual os sujeitos se autonomizam da dependência das ações de governo, da postura meramente reivindicativa de direitos, no sentido de não se submeterem passivamente às regras do jogo, impostas pelos segmentos dominantes e aparelhos burocráticos de Estado.

Portanto, não existe neste cenário uma alusão ao Grande Dia, uma espera messiânica da grande libertação e fim da alienação. A tarefa da dissolução das classes se torna a capacidade da classe dominada de fazer política, ou seja, de envolver os diversos atores políticos na 
solução de seus próprios problemas. Através da democracia progressiva, condicionada pelo continuo progresso social, por uma participação política cada vez mais intensa das classes subalternas nos governos, que as rupturas com a agenda hegemônica pode ocorrer (Moraes, 2002: 92).

Como afirma Nogueira (2004) embora uma democracia não possa ser concebida sem participação, para que se reflita em uma radicalização democrática, é necessário identificar de que forma os espaços são apropriados pelos cidadãos e seu potencial de transformação das relações sociais, para que a participação não se torne uma retórica estéril sem reflexos efetivos de mudança da realidade.

\section{Democracia e representação}

O Estado capitalista, de acordo com Viana (2003), esteve historicamente impresso na forma de dois regimes políticos: a ditadura burguesa aberta e a ditadura burguesa oculta, que seria a própria democracia moderna. A dinâmica do desenvolvimento capitalista irá promover mudanças na democracia burguesa e isto está intimamente ligado ao processo de transformação do Estado capitalista, resultado da luta de classes (Ibid, 2003: 33).

O conceito moderno de democracia, afirma o autor, teve suas origens no feudalismo europeu e que culmina no capitalismo liberal, com marcos como a Carta Magna e a Revolução Gloriosa de 1688. Estes eventos marcaram a ascensão das classes proprietárias e afirmação dos privilégios destas sobre a monarquia, já que esses não foram processos de libertação dos camponeses da dominação política de seus senhores e proprietários, mas sim a afirmação da independência da classe burguesa em relação à monarquia, separando assim a esfera econômica da política. Diferentemente deste contexto, os princípios constitucionais modernos pautaram- se pelas ideias de governo limitado e da separação dos poderes que deslocaram as implicações do governo pelo demos - com o equilíbrio de poder entre ricos e pobres - como o critério central de democracia.

[...] A conquista da democracia moderna e do sufrágio universal certamente representou um enorme avanço histórico, mas no final o capitalismo ofereceu uma nova solução para o velho problema entre governantes e produtores. Já não era necessário corporificar a divisão entre privilégio e trabalho numa divisão política entre governantes apropriadores e os súditos trabalhadores, uma vez que a democracia poderia ser confinada a uma esfera política formalmente separada, enquanto a economia seguia suas próprias regras. Se já não era possível restringir o tamanho do corpo de cidadãos, o alcance da cidadania podia então ser fortemente limitado, mesmo sem a imposição de limites constitucionais. (Wood, 2003: 174). 
A antiga ideia grega de democracia foi derrotada por uma concepção completamente nova de democracia. O momento crítico dessa redefinição teve suas origens nos Estados Unidos, na figura da democracia representativa. A fórmula para que o poder dos cidadãos fosse diminuído é a marca registrada da democracia moderna e o ponto principal no qual se diferencia da democracia ateniense. Como afirma Wood (2003: 186) na democracia representativa os sapateiros e ferreiros são representados por seus superiores sociais.

Nesse sentido, o povo não era definido como a demo ateniense comunidade ativa de cidadãos - mas como um conjunto desagregado de cidadãos limitados por seus direitos e deveres e cujo aspecto público era representado por um Estado central distante. O governo pelo povo continuou a ser o principal critério da democracia, entretanto um povo despolitizado, pluralizado, esvaziado de conteúdo social. O resultado foi tornar ocultas as relações de produção, características do capitalismo, ao desagregar a sociedade, sem nenhum poder superior, nenhuma unidade totalizadora. A desvinculação do Estado (esfera política) da sociedade civil (esfera social) enfraqueceu nela a luta contra o capitalismo (Ibid, 2003).

Em comparação com a noção antiga de cidadania - participação na comunidade política - até mesmo o conceito de direitos individuais, que talvez seja a maior prova de superioridade da democracia moderna sobre a antiga, trouxe uma conotação de passividade (Chaves, 2008). Deslocou-se a democracia para uma esfera puramente política, distinta e separada da sociedade civil e da economia. Em Atenas, não havia uma divisão clara entre estado e sociedade civil e não havia uma economia distinta e autônoma. Democracia formal ou representativa foi esvaziada de conteúdo social, os direitos políticos deixaram intactas as relações de dominação, de propriedade e de poder (Nogueira, 2004).

\section{Participação Social}

De acordo com Motta (1987), o interesse pela participação no âmbito dos estudos em gestão, nasceu nos anos 60 e 70, quando o conflito social inerente às organizações, passou a se tornar central para os teóricos americanos e europeus. Como afirma o autor, o que se colocou para este campo de estudos e pesquisa, não foi tanto a supressão do conflito, mas a possibilidade de antecipá-lo e controlá-lo, já que a coação física já não se mostrava eficaz. Por outro lado, a participação também foi um processo de conquista, por parte dos movimentos sindicais grupos sociais, evidenciando assim seu caráter dúbio.

A participação, dessa forma, não é e não pode ser vista apenas como uma artimanha manipulativa dos capitalistas e altos burocratas. Sem dúvida ela também o é, mas o seu outro lado não é menos importante. Ela é uma conquista e uma arma dos trabalhadores (Motta, 1987: 15). 
No âmbito da gestão pública, Boron (2011) assinala que desde os anos 80, organismos internacionais como o Banco Mundial e o FMI passaram a dar especial atenção ao tema participação, tendo em vista a perda de credibilidade de estados nacionais do Terceiro Mundo. Para pressionar os governos, esses órgãos têm estabelecido condições para obtenção de apoio financeiro e político, nomeadamente na promoção de ajustes fiscais, descentralização, participação e programas contra a pobreza.

Grande parte dos esforços, nesse sentido, deriva de um tipo de participação estritamente instrumental, denominada por Nogueira (2004) de participação gerencial, que não possibilita uma alteração política efetiva, nem das relações de dominação existentes. O aparelho burocrático governamental não é impermeável à incorporação de elementos da vida democrática, não apenas para adquirir maior transparência, legitimidade e responsabilidade, mas também para que as decisões possam refletir as reais necessidades e expectativas do cidadão (Ibid, 2004: 11).

Historicamente, os grupos e movimentos sociais seguem trajetórias e adotam estratégias que combinam diferentes graus de consciência política e participação. No campo das estratégias, de acordo com Spicer e Böhm (2006), os movimentos e organizações sociais podem utilizar a própria política institucional como espaço de resistência. Entretanto, esta estratégia depende de modos hierárquicos de organização e representação, já que a política oficial é composta por canais oficiais como formas burocráticas de comunicação e autoridade (Ibidem, 2006: 10). Estes tipos de organizações, denominados Movimentos Sociais Organizados (MSO), são eminentemente formalizados, atuando por meio de representação para articular os interesses de diferentes atores sociais.

Por outro lado, a estratégia infra-política caracteriza-se pela luta direta, através de organizações não hierárquicas, sendo a coordenação de suas ações mais informal, evitando o compromisso com grupos dominantes ou governos. Isto favorece a luta direta pela reivindicação de direitos. [...] os movimentos têm práticas organizacionais mais fluidas e táticas diretas, o que traz uma dificuldade para as elites repressivas localizarem os movimentos e os seus participantes. (Ibidem, 2006: 13-14).

Já o local de luta no qual se desenvolvem as práticas das estratégias políticas dos movimentos e grupos sociais podem ser as reuniões públicas, as ruas, as associações, as escolas, as redes de comunicação, os espaços institucionais da gestão pública, enfim, o cotidiano das relações (Gameiro, 2009). Ou seja, o local de origem da luta, se dá no seio da sociedade civil.

Tomando a democracia moderna e a sociedade de classes, Nogueira (2004) tipificou cinco modalidades de participação, que se combinam e coexistem historicamente de diferentes formas, expressando também, diferentes graus de consciência política, correspondendo a diferentes graus de maturidade, homogeneidade e organicidade dos grupos sociais e, no caso 
da gestão pública, vínculos entre Estado e sociedade civil e maior ou menor relação com a democracia autêntica.

A participação assistencialista, por exemplo, é um tipo de participação social no qual segmentos marginalizados são representados por instituições que lutam por condições mínimas de vida para estes segmentos. A participação corporativa ou gerencial é voltada à defesa de interesses de determinados grupos, como segmentos sociais e profissionais. Estes dois tipos de participação assistencialista e corporativa - de acordo com Nogueira (2004), são pré-políticas, pois os grupos negociam sua adesão à sociedade moderna e não visam uma transformação social a longo prazo, mas negociações pontuais em curto prazo. Já a participação eleitoral é característica de cidadãos maduros, que se afirmam não apenas em relação a si próprio e interesses individuais, mas também em relação aos outros (direitos políticos). A participação política é a prática ético-política que visa substituir as desigualdades por igualdade moral e que disputa o poder e governo da vida coletiva, bem como a direção moral e intelectual da sociedade. Organiza-se por meio da autoorganização popular, no qual os sujeitos se articulam politicamente, interferindo diretamente e lutando pela democratização do poder. Prioriza a participação direta, e tem como horizonte resgatar os laços orgânicos entre Estado e sociedade civil, numa mudança de cultura política, em prol da transformação social (Nogueira, 2004).

O cunho político da participação depende em grande parte de uma conscientização e educação que qualifica a participação, que pode ser adquirida por meio de experiência, na qual se dissemina a capacidade de valorizar as instituições políticas. A consciência política se desenvolve através da experiência e vivência em diferentes espaços onde se priorizam preceitos éticos, que questionam a realidade, que podem ser escolas, espaços culturais, associativos e espaços públicos de gestão (Motta, 2003).

\section{Procedimentos metodológicos}

Como defende Gameiro (2009: 49) a história como suporte metodológico, é um elemento central de contextualização e apropriação adequada do significado dos fenômenos. Para construir o retrospecto histórico do Programa Descentralização da Cultura de Porto Alegre foram feitas visitas sistemáticas ao campo empírico. Paralelamente a isso, através de um levantamento e análise documental em jornais, relatórios, editais, documentos internos e revistas, construímos a base de dados secundários.

Foram realizadas entrevistas semiestruturadas aos idealizadores e coordenadores do Programa, que permitiram identificar os elementos centrais da proposta política do Programa.

Através da análise documental e entrevistas semiestruturadas com oficineiros, líderes comunitários participantes do Programa, identificamos 
as características da participação nos discursos e expressões artísticas produzidas. As entrevistas foram complementadas por conversas informais e observação participante com o apoio de notas de campo.

Para significar e organizar os dados foi utilizada a Análise de Conteúdo que envolve técnicas de análise das comunicações e procedimentos sistemáticos e objetivos do conteúdo das mensagens em três etapas propostas por Bardin (1977): 1) a Pré-análise, ou a fase de organização para tornar operacional e sistemática as ideias iniciais; 2) a Exploração do material, ou a definição de categorias, descrição analítica, codificação e classificação e; 3) o Tratamento dos resultados na qual os resultados brutos são interpretados de maneira a serem significativos e válidos.

Nas etapas 2 e 3, definimos algumas categorias e elementos que nortearam a apresentação dos dados e análise:

\section{Quadro 2: Elementos norteadores da identificação das características da participação no Programa}

\begin{tabular}{|c|c|c|}
\hline ELEMENTO & CATEGORIA & O QUE PROBLEMATIZAR NA REALIDADE \\
\hline $\begin{array}{l}\text { Organização da } \\
\text { participação }\end{array}$ & $\begin{array}{l}\text { Impulso da participação } \\
\text { (poder público ou sociedade } \\
\text { civil) } \\
\text { Ênfase da participação (direta } \\
\text { x representativa) } \\
\text { Fluxo da tomada de decisão } \\
\text { (de cima para baixo ou de } \\
\text { baixo para cima) } \\
\text { Participação x níveis de } \\
\text { tomada de decisão }\end{array}$ & $\begin{array}{l}\text { Como nasceram os espaços de participação? } \\
\text { Como é organizada e participação (por representação, } \\
\text { direta)? } \\
\text { Como ocorrem as tomadas de decisão (de baixo pra } \\
\text { cima ou vice e versa)? } \\
\text { Em quais decisões as comunidades participam? } \\
\text { Existe uma pressão, nos espaços de participação, para } \\
\text { que se saiam de todas as discussões como uma } \\
\text { resolução? Existem "vazios decisionais"? } \\
\text { E esses são aceitos ou não? } \\
\text { Todas as decisões tomadas pelos participantes são } \\
\text { acatadas? } \\
\text { Quando não são acatadas, como os participantes } \\
\text { reagem? } \\
\text { Os participantes do processo se limitam a participar } \\
\text { apenas do Programa? }\end{array}$ \\
\hline $\begin{array}{l}\text { Objetivos da } \\
\text { participação }\end{array}$ & 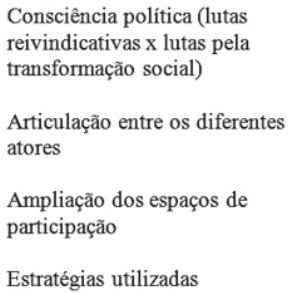 & $\begin{array}{l}\text { Os atores se reconhecem como pertencentes a um grupo } \\
\text { maior, classe social oprimida, ou apenas a grupos } \\
\text { divididos pelas comunidades? } \\
\text { Esta participação implica historicamente, na ampliação } \\
\text { da tomada da decisão e participação? } \\
\text { Quais os objetivos centrais da participação - auxiliar } \\
\text { populações carentes reivindicação de interesses } \\
\text { comunitários, discussão política, contestação da } \\
\text { realidade? } \\
\text { A expressão artística que é produzida reflete um } \\
\text { processo de conscientização e contestação da realidade? }\end{array}$ \\
\hline
\end{tabular}

\section{Por um horizonte de transformação social: a história do Programa Descentralização da Cultura de Porto Alegre}

Em 1989, na cidade de Porto Alegre, o Partido dos Trabalhadores venceu as eleições para a Prefeitura Municipal, com a promessa de resgatar 
o autêntico significado de democracia, ou seja, um governo que fosse do povo e para o povo. A sua proposta política tinha como eixo de atuação a descentralização da gestão pública através dos conselhos populares, se apropriando dos espaços criados a partir da auto organização popular nos anos 80. A proposta de governar através dos conselhos era a forma de empreender um novo padrão de gestão, nos quais os cidadãos eram participantes das formulações políticas, ou seja, sujeitos, e não objetos, das políticas públicas governamentais.

A reforma urbana e a reformulação da estrutura administrativa da cidade imprimiram novas formas de organização e participação dos movimentos comunitários. As discussões nos conselhos populares passaram a se centrar em torno de formulações políticas por áreas, como saúde, educação, infra-estrutura e cultura, e não mais por questões pontuais. Militantes e ativistas políticos apostaram num momento de aprofundamento democrático pautado pelo exercício da cidadania e participação ativa, no qual os atores se apropriariam conscientemente dos espaços de participação no governo e transformariam o Estado em um campo de disputas.

No entanto, como ressalta Nogueira (2004), nenhuma sociedade é imediatamente política, e são as contradições, as lutas e as disputas no seio na sociedade civil que movem esta politização. Para tanto, primeiramente os atores devem estar conscientes de sua realidade, marcada pela contradição e luta de classes. Para os movimentos sociais o campo da cultura era visto como um espaço politico de articulação entre lideranças e a população e de reconhecimento das contradições e articulação das lutas contra hegemônicas. Nesta perspectiva a cultura era compreendida em um sentido mais amplo no qual, por meio de expressões artísticas, as comunidades constroem uma consciência de coletividade e de cidadania. Um processo em que a produção artística não está dissociada da realidade, mas é reflexo dela, e pode ser utilizada como um instrumento para que os atores desenvolvam autonomia e rompam com os mecanismos de opressão, sendo sensibilizados e despertados para sua realidade. Sua principal contribuição se imprime na capacidade de manifestar interpretações que os coletivos têm do mundo à sua volta.

O cunho político se revela através da possibilidade de desenvolver uma consciência coletiva e estimular as comunidades a se organizarem e construírem consensos em torno da identidade de classe. Por meio desta articulação entre lideranças e comunidades em torno da produção cultural seria possível formar novas concepções, ações políticas, e consensos sociais que dessem força à luta contra hegemônica com vistas a uma transformação social. Foi com base neste projeto político, que o grupo de teatro de rua Ói Nóis Aqui Traveiz desenvolveu, no período em que o PT assumiu a Prefeitura Municipal, o Projeto Teatro como Instrumento de Discussão Social, tendo o apoio financeiro da recém criada Secretaria Municipal de Cultura (SMC).

A partir da entrada de um partido progressista no governo, que trazia dentro de suas propostas, a democratização e a descentralização 
cultural, o grupo procurou desenvolver, dentro do seu trabalho, ações em conjunto com a Secretaria Municipal de Cultura [...] Procuramos sair dos espaços habituais de teatro e sair para as ruas. Desde sua origem, o Ói Nóis Aqui Traveiz tem essa preocupação, uma abordagem diretamente política e articulada com movimentos populares que estavam surgindo nessa época[ ]A gente foi tendo contato com moradores de bairros e começou a vontade de se levar o nosso trabalho para as diferentes comunidades. Começamos os primeiros contatos, com as associações de moradores, e outras entidades[ ]E a partir daí, o Ói Nóis desenvolve o projeto de circuito regular de apresentações que existe até hoje, que a gente chama caminho para um teatro popular. Essa aproximação com os bairros também possibilitou o desenvolvimento do Projeto Teatro como Instrumento de Discussão Social [...]. Entrevista ao fundador e atuador do grupo de teatro de rua Ói Nóis Aqui Traveiz

Primeiramente por intermédio de um processo pedagógico de formação política em oficinas de teatro de rua, os atores sociais se apropriariam conscientemente dos valores democráticos autênticos, como consciência coletiva e luta pela participação em todas as esferas de decisão política na gestão, tornando as políticas culturais efetivamente públicas. Como ressalta Paulo Freire (2007), um projeto democrático de sociedade deve buscar a afirmação e adesão das classes dominadas, através do diálogo, discussão e conscientização, que pode ocorrer em espaços de formação democrática, que podem ser escolas, associações e, neste caso, oficinas de teatro de rua.

O Projeto Teatro como Instrumento de Discussão Social, assim como as oficinas de teatro nas fábricas, desenvolvidas pelo grupo Espalha - Fatos, que nasceu do movimento sindical de Porto Alegre, tinham como propósito qualificar e fortalecer a articulação e participação das comunidades nos espaços criados, por meio da reforma administrativa que ocorria da cidade no governo do PT. A ação deste grupos pautava-se pelo [...] combate à colonização e massificação culturais, democratizando o espaço da arte, atuando nas ruas e atingindo um público e trabalhando junto e a partir da realidade deste público, que, por suas carências econômicas e culturais, está afastado das salas de espetáculo (Alencar, 1997: 128).

Como ressalta Moraes (2002) a tarefa de ruptura com a dominação e a construção de uma sociedade efetivamente democrática está na capacidade dos diversos segmentos da sociedade civil de fazer política e de se envolver nos espaços de participação conscientemente. Só assim seria possível conquistar uma democracia, condicionada por uma participação cada vez mais intensa da sociedade civil no governo, promovendo a ruptura com a agenda política dominante.

Na contramão deste processo, a Secretaria Municipal de Cultura de Porto Alegre, criada no governo do PT em 1989, dando outro sentido à concepção de democracia, empreendia esforços para a desconcentração 
cultural do centro de cidade, levando atividades e eventos culturais para a periferia.

A Secretaria Municipal da Cultura, procura levar cultura a toda a cidade além de incentivar o desenvolvimento dos moradores das comunidades envolvidas. Associações, escolas, creches, CTGS, praças, parques e diversos locais se tornam referência como espaço cultural [...] A Administração Popular reafirma a estratégia de ação cultural que se expressa: na constituição de novos espaços, na promoção de valores locais e a circulação de bens culturais para ampliação do acesso, formação de público e democratização do fazer cultural [...] Possuir uma referência edificada, um endereço da cultura, um equipamento que tenha as condições específicas adequadas à expressão da atividade artística (SMC/POA, 1992, grifos nossos).

A concepção de cultura subjacente era a produção artística tradicional que, naquele período, era dominada pela indústria cultural e pelo movimento tradicionalista gaúcho, leituras dominantes no cenário cultural de Porto Alegre. As políticas da SMC mantinham os privilégios e domínio das classes dominantes no contexto municipal. Como aponta Dorneles (2001), mesmo apresentando uma proposta de democratização cultural, era possível identificar no discurso da Secretaria Municipal de Cultura a concepção dominante de cultura que ainda se resumia às produções artísticas da classe artística tradicional. Esta perspectiva não rompia as políticas do período da ditadura militar, quando os centros comunitários desenvolviam atividades culturais com o objetivo de educar e tornar os moradores das comunidades e o convívio social mais civilizado. A participação social era concebida como a participação passiva e amistosa das populações. Na definição de Nogueira (2004), uma participação eminentemente gerencial, com vistas à sustentabilidade política.

Entretanto, a pressão social dos grupos de teatro de rua e dos movimentos comunitários, e o aumento na participação popular no Orçamento Participativo, forçaram a SMC a mudar a concepção de descentralização cultural.

Me parecia que a política de descentralização efetiva devia ser natural, como algo de uma política pública cultural decente. Não existe uma política pública na área da cultura sem pensar a diversidade a descentralização. Isso tornaria uma política pública algo inviável. Cada bairro, cada vila, pulsa algo diferente, é importante que sinta e viva sua cultura a partir da sua região, das suas relações, e é isso que de fato é a cultura, é a troca, a construção, as relações []Mas foi difícil no início fazer a prefeitura entender isso, que ninguém leva cultura para ninguém. Entrevista ao fundador do grupo Espalha Fatos.

Esta pressão culminou na criação de um programa de governo voltado 
para a produção cultural das comunidades, o Descentralização da Cultura em Porto Alegre (DCP). A própria concretização do Programa foi uma conquista dos grupos culturais, modificando valores sociais e pressupostos das políticas públicas culturais, através da valorização da cultura local e envolvimento de segmentos sociais, principalmente aqueles historicamente marginalizados, nos processos de fruição, produção, gestão e formação cultural. Esta conquista fortaleceu o movimento de politização das comunidades, bem como a disputa destas pelo poder, tendo em vista que até então o poder de decisão a respeito das políticas públicas culturais estava sob responsabilidade exclusiva da Secretaria Municipal de Cultura.

A Administração Popular, desenvolveu em Porto Alegre a estratégia da ação cultural com a participação comunitária através do Projeto de Descentralização da Secretaria Municipal da Cultura (SMC). A ação cultural de Descentralização é promotora do espaços democráticos da realização da cultura pelo sujeito popular, da adesão espontânea ao serviço público, do encontro para planejamento da ação. A ação cultural em um lugar é apenas uma das possibilidades da população deste lugar. Não sendo obrigação, torna-se alternativa. Sendo buscado por demanda ou informação da existência do serviço, é querido. Sendo querido, é protegido como seu, pretendido como permanente, valorizado como conquista, preservado de danos de circunstâncias adversas externas. É fazer público comunitário experimentado coletivamente. Em consequência da programação, a própria comunidade que a abriga se integra e se organiza, diz a sua palavra, conta a sua história, incorpora os fatos à sua história, requer a permanência da ação também por seus efeitos em outros aspectos da vida social, desde a promoção da autoestima até mesmo aos resultados dela junto ao mercado, passando pela satisfação pessoal da realização coletiva ou fruição individual do fazer cultural. O sujeito popular que se envolve desta forma consciente se torna indisponível à ocupação, à usurpação, à manipulação. A partir da realização participativa com a comunidade, a ação cultural pública se realiza como um serviço público devido pelo Estado [...] (DSC/ POA, 1994, grifos nossos).

Em oposição às ações de desconcentração do início dos anos 90, o Programa Descentralização da Cultura propunha valorizar a cultura popular através da ampliação do poder das comunidades sobre as determinações governamentais e estímulo à sua autonomia.

[] eu não podia chegar com um espetáculo pronto e dizer, aqui está o espetáculo que vocês vão apresentar, isso era contraditório a nossa proposta. O que eu fazia, eu levava diversas opções de texto e abria também para quem quisesse levar algo e discutíamos qual o espetáculo que eles queriam apresentar. Porque esse espetáculo e não aquele, enfim, existia uma forte discussão []. Entrevista ao fundador do grupo Espalha Fatos. 
As oficinas de teatro do Projeto Descentralização norteiam-se pelo enraizamento da cultura como práxis, alheia a política que se limita ao financiamento do produto ou apenas a promoção de eventos. Nesse sentido, descentralizar torna-se sinônimo de democratizar, pois visa ao estímulo do fenômeno artístico-cultural em diversas regiões da cidade, transferindo a linha de ação política para a periferia (Massa, 2004: 12).

Esta foi a realidade nos primeiros anos do Programa, entre 1994 e 1997, quando a experiência rendeu frutos em termos de ampliação e politização da participação das comunidades, bem como democratização e deselitização da gestão pública. Muitos movimentos comunitários superaram, neste período, uma postura meramente reivindicativa, assumindo uma atitude propositiva nos espaços públicos. Foi um período de maior valorização à diversidade cultural e produção local.

Discutíamos muito a importância das comunidades criarem um centro comunitário. Eu lembro que na Restinga nós construímos um centro comunitário a partir da discussão das oficinas. Ocorriam vários problemas nas comunidades que foram resolvidos a partir das oficinas, porque era um momento de encontro e discussão das comunidades [] Teve várias situações problemáticas nos bairros que foram resolvidas a partir da ação cultural do Descentralização. Em função desse auto olhar e grupos que surgiram []. Entrevista ao ex-oficinando de teatro de rua na Restinga e um fundadores do grupo Ars Longs Vitta Brevis.

O início do Programa e do planejamento de suas ações se deu através da criação de comissões de cultura nas regiões organizativas do Orçamento Participativo. Estes eram espaços de diálogo entre poder público e comunidades que foram importantes para a organização das demandas e definição do cronograma de atividades de cada região. A coordenação do Programa buscou resgatar as experiências dos grupos de teatro de rua e estabeleceu como eixo central de trabalho o desenvolvimento de oficinas de artes das comunidades, que antes eram coordenadas por grupos autônomos e que tinham apenas o apoio financeiro da SMC. O projeto das oficinas do Descentralização teve como referência principal as experiências de oficinas já existentes do Grupo Ói Nóis Aqui Traveiz, focando no conteúdo político destes espaços, não apenas como simples atividades de lazer mas, pelo contrário, de conscientização e politização, qualificando assim o processo de descentralização iniciado pelo governo.

Através do engajamento dos coletivos e do trabalho realizado nas primeiras oficinas, o Programa ganhou adesão e confiança da população, como afirma o atuador Paulo Flores do grupo Ói Nois Aqui Traveiz, que na época era oficineiro do Programa: esse período primeiro, é um momento que o teatro tem uma importância muito grande, o teatro conseguiu de alguma maneira vencer as dificuldades iniciais, de oficinas artísticas em bairros, tendo um resultado muito positivo. 
O reflexo se evidenciou na ampliação dos espaços de participação dentro e fora Programa, e na criação dos projetos cultura PURA AQUI e Festival de Música, que estimulavam e valorizavam os artistas locais. A criação de um espaço específico no Orçamento Participativo, para discutir as políticas culturais, também foi uma vitória, já que até o ano de 1996 as políticas culturais eram discutidas juntamente com as políticas para esporte e lazer.

Foi maravilhoso pois havia um intercâmbio entre os grupos, as regiões. Tivemos oficina com Augusto Boal do teatro do oprimido. Essa experiência transformou, modificou profundamente. Formamos um grupo de teatro e partir das oficinas, o Bacantes. Tem muitas pessoas que nasceram do Descentralização e estão envolvidas com atividades culturais na cidade a fizeram a diferença no cenário cultural da cidade []. Entrevista a um ex-oficinandos e fundador do grupo Bacantes.

Comecei a fazer a oficina de teatro na Restinga Montamos uma apresentação que era a festa junina, mas que já tinha um fundo político...Tinha uma troca entre os grupos que foi super importante Foi um período de efervecência cultural na cidade, eram coisas novas, um momento de descobertas Muitos grupos surgiram das oficinas Nós criamos o grupo de teatro Ars longa vitta brevis e participávamos ativamente das discussões sobre questões culturais no bairro nos unimos com outro grupos para criar o Núcleo de Cultura da Restinga que consegiu fundos para realizar anualmente a semana da Restinga [...]. Entrevista a um ex-oficinando de teatro de rua na Restinga e fundador do grupo Ars Longs Vitta Brevis.

Outro fruto deste período foi a democratização de espaços e aparelhos culturais, como o Teatro São Pedro, Teatro Renascença e Porto Alegre em Cena, que antes eram utilizados apenas pelas elites da cidade. Uma das ações desenvolvidas pelo Programa era trazer e oferecer para os moradores das periferias a possibilidade de assistir e inclusive se apresentar em espaços historicamente freqüentados pelas elites locais.

A questão da cultura até o momento da descentralização não era acessível as comunidades, tu tinhas que vir para o centro, para galerias, cinema, teatroAs pessoas acabaram se apropriando desses setores que eram só para os privilegiados, ou seja, foi um salto em termos de democratização. As pessoas, além de participarem das atividades nas comunidades, participavam nos equipamentos culturais Elas conseguiam desenvolver um outro olhar, não de artista mas de alguém que tinha interesse [...]. Entrevista a um oficinando de artes plásticas e ativista cultural.

Me levaram para assistir vários espetáculos A gente tinha acesso a ingressos gratuitamente através do projeto. A descentralização promovia trocas entre grupos e oficinas Na época que eu fui oficineira 
já não fazia mais Então o pessoal da Restinga foi fazer oficina comigo, e o oficineiro deles era o Paulo Flores do Ói Nois Aqui Traveis. Então eu conheci materialmente o Paulo Flores e depois vim a trabalhar com eles vários anos. Também a gente foi visitar a oficina de Restinga, então eu conheci outras pessoas da mesma idade, na mesma condição financeira e social que eu Eu diria que foi o melhor começo que eu poderia ter tido Foi o único começo que eu poderia ter tido []. Entrevista a uma oficinanda de teatro no Vila Vicente Montegio e oficineira do Programa nos anos 2004 e 2006.

O maior envolvimento das comunidades nos espaços de discussão das políticas públicas culturais resultou num aumento expressivo na temática de cultura do OP, bem como no orçamento da SMC e naquele destinado ao Programa Descentralização. Como ressalta Nogueira (2004), a ativação do projeto democrático depende, em grande medida, de uma melhor articulação entre os interesses, valores e opiniões, através de sua representação em instituições associativas e representativas, construindo, através da disputa política, a busca da criação de consensos.

O interesse nas reuniões do OP sempre eram voltadas para o departamento de água e esgoto, entre outros assuntos de primeira necessidade. O tempo destinado para a cultura era mínimo, o único interesse era saber onde tinha sido aplicado a verba da cultura. Com o passar do tempo as comunidades passaram a compreender a importância das atividades culturais e perceberam que a arte, a cultura são formas de articulação. O tempo para debater cultura começou a aumentar, passou de 5, 10, 15 minutos e assim por diante. Quando as comissões passaram a discutir por uma hora apenas a cultura, o OP criou um espaço específico para a cultura [...]. Entrevista ao idealizador e coordenador do DCP de 1993 a 1996, e 2003.

[...]Esse resultado estimulou a participação, tanto por parte da prefeitura, quanto por parte das organizações sociais presentes no OP. A gente viu um crescimento nessa questão da discussão da cultura, lembro que no início a cultura era um tema que estava dentro das temáticas junto com educação e lazer A cultura tomou uma dimensão tão grande nas discussões Isso fez o teatro nesses primeiros anos ter um significado muito grande no sentido de mobilizar e estimulador das pessoas [...]. Entrevista ao fundador do grupo Espalha Fatos.

Esta experiência também foi importante em termos de auto organização popular. Em regiões periféricas como a zona Leste, a Restinga e a Lomba do Pinheiro foram criados núcleos culturais, e coletivos se formaram a partir das oficinas. As comunidades puderam organizar e construir suas próprias políticas e consensos que fortaleceram a participação nas comissões, não reduzindo sua participação aos espaços institucionais. A participação política, como aponta Nogueira (2004), não pode reduzir a atuação política à gestão pública, por isto a importância de articulação de 
espaços de discussão para além da esfera governamental, para que as ações políticas não se restrinjam à gestão.

Todas estas ações possibilitaram o reconhecimento e articulação ampla entre os diversos atores sociais, comunidades e regiões. Estas trocas desenvolveram uma identidade entre as comunidades, que superava os limites de bairro, de região, de cidade e que se construíram em torno de uma identidade de classe marginalizada. O envolvimento das comunidades nos espaços abertos a partir do Programa teve como consequência uma mudança no desenvolvimento simbólico municipal e na formação de concepções e práticas políticas, transformando o campo da cultura em um espaço político e de luta pela transformação social.

Sob esse ponto de vista, a trajetória das Oficinas Populares de Teatro nos primeiros anos de atividade não deixou de educar, pois desenvolveu aprendizagem por meio da cultura... Tornou-se espaço de formação de atuadores: mas acima de tudo, promoveu a socialização das comunidades por meio do fazer artístico, desempenhando a função primordial da cultura de unir as pessoas e criar ao redor de um núcleo sentimentos e percepções comuns... Na prática, o princípio de descentralização nas Oficinas de Populares de teatro não se limita à noção de criar núcleos artísticos fora do centro. A valorização dos bairros e a resolução de seus problemas por meio da conscientização social Nele, como se pode supor, não há alguém mais culto que vem do centro e fornece conhecimento aos da periferia, ou que está disposta a aprender com os excluídos [] (Massa, 2004: 72).

Neste periodo, preponderaram as estratégias de participação política. Muito embora os primeiros espaços tenham sido criados a partir do Programa, a auto organização de moradores de diferentes bairros, com vistas à luta pela mudança dos pressupostos da gestão cultural, possibilitou a abertura de novos espaços de participação e a ampliação dos níveis de decisão das políticas públicas culturais. Os movimentos sociais, neste periodo, lançaram mão de estratégias institucionais e infra-políticas, utilizando não só os espaços existentes na gestão pública, mas também nas ruas, associações dos bairros, entre outros.

Como havia essa dinâmica de discussão isso estava presente e crescia nas comunidades. Naquele momento ninguém iria entrar no Programa sem antes passar por essa discussão. Isso estava em todas as áreas A coordenação apresentava os projetos de oficinas que foram levados até ela, mas as comissões é quem decidiam quais oficinas, quem era o oficineiro, quando e onde as oficinas iam acontecer []. Entrevista ao fundador do grupo Espalha Fatos.

No entanto, como a sociedade civil é um campo de lutas (e este é principal motor de sua politização) e a luta hegemônica é uma constante disputa, a grande imprensa, que representava os padrões dominantes de 
cultura - a indústria cultural e movimento tradicionalista gaúcho buscou resgatar o espaço perdido e sua centralidade no campo das políticas culturais.

Como estratégia de enfraquecimento dos movimentos comunitários que se fortaleceram em Porto Alegre no início da década de 90, a grande imprensa veiculava duras criticas a acontecimentos como o festival de música, que favorecia grupos populares iniciantes ou, a presença nos espetáculos no Teatro Renascença de moradores das periferias (e participantes das oficinas).

[...] Foi um período de terrível embate com a prefeitura, um processo confuso pois gerava na secretaria um sentimento de perda de poder e de controle sobre o Projeto [...] Aprendemos a brigar a lutar pelo que queríamos e não íamos mais aceitar estas imposições [...]. Entrevista a um ex-oficinando de teatro de rua na Restinga e fundador do grupo Ars Longs Vitta Brevis.

A terceira gestão do Partido dos Trabalhadores em Porto Alegre que teve inicio em 1997, foi especialmente conflituosa entre Secretaria Municipal de Cultura e os grupos de teatro de rua, os grupos de cultura locais e as comunidades organizadas. A luta destes segmentos da sociedade civil em defesa da cultura como um direito social de todos os cidadãos se enfentava à SMC que buscava o apoio dos grandes meios de comunicação e, para isso, resgatava políticas baseadas em padrões culturais excludentes e centralizadores. Decisões que haviam sido tomadas anteriormente nas comissões, como continuidade de oficinas, e apoio financeiro do Programa às atividades da escola de teatro popular Terreira da Tribo, não foram continuadas e a SMC passou a centralizar as decisões.

Eu lembro que a coordenação, no início, tinha a mesma visão que nós, de construir tudo coletivamente e democraticamente, e que esse processo de construção coletiva é um processo de negociação, eu não posso querer impor a minha posição sobre a tua...Nos primeiros anos, isso acontecia... Depois que mudou a coordenação, o primeiro espetáculo montamos eles queriam impor um outro espetáculo para o grupo do CECOPAN Eu disse - isso não pode, nós temos que discutir com o grupo, fazer todo o processo e avaliação. Eles disseram que o grupo não estava preparado para o espetáculo que havia escolhido e eu disse - e daí, nós não queremos formar atores, nós queremos formar cidadãos, pessoas mais conscientes - nós queríamos ir construindo isso. Mas a coordenação ainda assim, queria impor algo. Gerou um conflito aquilo, porque fomos contra e não acatamos a ordem que vinha da coordenação [...].Entrevista ao fundador do grupo Espalha Fatos.

Estas políticas resgatavam o caráter elitista anterior e reeditavam o cunho catequizador que buscava a formação de público e participação passiva em atividades produzidas pelo poder público. O movimento de centralização do poder decisório na coordenação do DCP ficava evidente e 
deixava para as comissões e comunidades apenas a execução das ações. A face autoritária da SMC se revelava na desconcentração das ações culturais, sem descentralizar o poder de decisão e controle. Este foi um período de retrocesso e descaracterização da ideia inicial do Programa que gerou tensão com os atores sociais que haviam nascido e se fortalecido nos anos anteriores.

Os grupos de teatro de rua que inspiraram o Programa - Ói Nóis Aqui Traveiz e Espalha Fatos - e que foram pioneiros na realização de oficinas artísticas com cunho social e político nas comunidades da periferia de Porto Alegre, resistiram a este processo centralizador por meio de mobilizações, da realização de espetáculos de rua que criticavam a SMC e o governo. Em 1998, quando houve uma mudança de coordenação e eixos de atuação do Programa DCP, estes grupos foram desligados de maneira autoritária.

O que aconteceu, a descentralização acabou tirando todas as pessoas que eram oficineiras do grupo do programa ou cooptando... A partir de 98 existe um boicoto ao trabalho do nosso grupo. É um momento que depois desse período de crescimento e fortalecimento das comunidades entre 93-97 existe um desgaste principalmente na característica de uma proposta definida - o que quer as oficinas culturais nos bairros, o que busca esse tipo de trabalho? Acho que aí começa o Projeto que idealizamos a se perder, no meu entendimento []. Entrevista ao fundador e atuador do grupo de teatro de rua Ói Nóis Aqui Traveiz.

Como forma de resistir ao retrocesso político é exercida pressão para que as comissões fossem incluídas na estrutura do OP, passando a ser a primeira etapa das demandas para a Temática de Cultura. Deste modo, as comissões, que discutiam políticas para a região, qualificaram as discussões políticas para a cidade na Temática de Cultura. Além disto, as comissões teriam mais um espaço de pressão social sob o poder público, já que as demandas de atividades para as regiões chegavam para a coordenação do DCP via Temática e comissões.

Isto ampliou a atuação do Programa na cidade e as regiões receberam mais atividades, espalhadas entre os bairros. Entretanto, este crescimento na abrangência do Programa não foi acompanhado de uma maior qualificação e aprofundamento da participação. Pelo contrário, com o enfraquecimento da participação direta nas comissões, as discussões no orçamento Participativo reduziam-se a reivindicações e disputas entre as regiões, e não uma articulação em prol da democratização das políticas públicas culturais.

Mas é importante lembrar que a articulação quando as demandas passam pelo OP não era mais das pessoas, população Era muito em função das lideranças, quando elas queriam conseguiam trazer muitas pessoas para o OP para votar culturaIsto porque depois acabou enfraquecendo o envolvimento popularNão era da massa, do 
povo...Depois de um tempo acabou sobressaindo as decisões das lideranças dos bairros, que são ligadas a arte, a cultura, ou que tem interesse nisso também [...].Oficinando de artes plásticas em 96, 97 e 98 e ativista cultural em 2002 e 2003.

Neste momento, a participação que preponderava no Programa se distanciava de um projeto de democracia autêntica, no qual a participação direta é pressuposto deste processo. A participação passou a ser concebida como representação das comunidades nos fóruns do OP preponderância das estratégias infra-politicas. Os grupos, para continuar no Programa, tiveram que reduzir sua participação aos espaços delimitados na gestão pública. Esta desarticulação se refletiu em disputas menores que passaram a priorizar questões comunitárias, não mais pautadas pela construção de um consenso social em torno da democratização e deselitização das políticas públicas culturais e disputa pelo poder, mas pela exigência e disputas por determinadas atividades para as regiões. Em suma, entre os anos 1998 a 2001, preponderaram, no Programa DCP, práticas e estratégias de participação gerencial.

Como enfatiza Nogueira (2004) a capacidade do sistema político, neste caso, as comunidades de produzir consensos sociais, aproxima a sociedade civil da sociedade política. Entretanto, fragmentada pelo reforço da pluralidade de interesses corporativos e práticas de participação preponderantemente comunitárias, os movimentos da sociedade civil enfraqueceram seu potencial político, já que não contestavam mais os arranjos dominantes da gestão municipal.

Em 2002 o PT venceu as eleições para presidência da republica, o que favoreceu a gestão municipal. Com sua chegada ao governo federal, as políticas públicas passaram a imprimir um caráter ampliado do próprio conceito de cultura, entendida enquanto condição e objetivo do desenvolvimento humano (Vilutis, 2009: 57). Conceito este que estava presente também no discurso do Programa Descentralização, mas que não havia pautado as práticas do Programa nos últimos anos.

A política Cultural no Brasil retoma o sentido original da palavra Cultura e se propõe a cultivar as infinitas possibilidades de criação simbólica expressas em modo de vida, motivações, crenças religiosas, valores, práticas, rituais e identidades [...] As políticas culturais devem reconhecer e valorizar esse capital simbólico, através do fomento a sua expressão múltipla, gerando qualidade de vida, autoestima e laços de identidade e diversidade entre os brasileiros. Diversidade que se expressa em práticas, serviços e bens artísticos e culturais determinantes para o exercício da cidadania, a expressão simbólica e o desenvolvimento socioeconômico do País (Brasil, 2006).

Assim, o governo do PT incorporou no discurso oficial um forte ideal de democratização, entendido como a participação da sociedade civil 
na gestão pública, num processo que fortaleceria o exercício da cidadania. Nesse sentido, o projeto político nacional englobou a descentralização e a participação da sociedade civil, os mesmos elementos presentes na proposta política em Porto Alegre, que se refletiam principalmente na formulação das políticas públicas culturais.

Entretanto, âmbito municipal, os conflitos existentes entre o poder público e os grupos locais evidenciavam o antagonismo da proposta de democratizar a cultura. A fim de resgatar o dialogo com as comunidades historicamente aliadas ao partido, a Secretaria Municipal de Cultura reestruturou o Programa criando núcleos setoriais formados por ativistas culturais, em sua maioria moradores das comunidades que haviam participado do Programa. Estes eram responsáveis pela supervisão dos trabalhos desenvolvidos nas oficinas de artes cênicas, artes plásticas, cinema, vídeo e foto, literatura, capoeira, memória cultural, música e inclusão cultural. O propósito era resgatar o diálogo com as comunidades, revitalizando as comissões de cultura e reaproximando a coordenação da população.

Os ativistas eram também responsáveis por, junto com os oficineiros, estimular as discussões nas comissões de cultura regionais, que haviam se esvaziado no período anterior. Para tanto, várias estratégias foram desenvolvidas, como a realização de um cronograma de palestras e discussões nas comissões em torno de determinadas temáticas - questões indígenas, identidade negra, cultura popular, entre outros. Dali saíam as decisões que eram levadas pelos ativistas até à coordenação do DCP. Isto, em certa medida, gerou a ampliação da participação nas comissões.

Entretanto é importante ressaltar que esta revitalização das comissões não foi acompanhada na ênfase da participação direta e resgate da democratização das decisões do Programa, já que decidir o quê e como fazer ficava sob a responsabilidade da Coordenação e dos representantes das comunidades na coordenação do Programa.

Este ampliação na participação de entidades que lutavam por maior investimento em políticas culturais se expressou na priorização do campo da cultura no Orçamento Participativo, e na conquista, em 2004, de um orçamento de cerca de 1,4 milhão para o Programa. No entanto, no final deste ano, o Partido dos Trabalhadores perdeu as eleições municipais para o PMDB, que elegeu José Fogaça.

Em novembro de 2004, os oficineiros foram notificados que as oficinas iniciadas naquele ano seriam encerradas antes do tempo previsto, o que provocou novas pressões para forçar a continuidade do ao Programa até o final do mandato.

Esta transição do governo gerou o temor dos grupos locais pela vinculação à temática de cultura do Orçamento Participativo. Deste modo, a coordenação do DCP perdeu sua autonomia orçamentária e decisória para o OP. Mas a estratégia não resistiu ao esvaziamento promovido pela 
Prefeitura do PMDB e o Programa foi quase extinto. Suas políticas culturais dirigiam-se preferencialmente para o fortalecimento do patrimônio histórico e da identidade gaúcha, eximia maneira de mascarar as contradições de classe e as relações de exploração. Novamente, a concepção de democratização cultural foi associada, pela Secretaria Municipal de Cultura, sob o comando do PMBD, à ideia de desconcentração cultural do centro da cidade, levando atividades para as comunidades e concebendo a participação passiva das comunidades em atividades elaboradas pela SMC.

Com o orçamento reduzido em aproximadamente 90\% o Programa Descentralização ficou limitado, em 2005, à oferta de oficinas para as comunidades. As discussões nos espaços de participação direta - as comissões de cultura regionais - se enfraqueceram, pois não ecoavam nos fóruns do OP, que neste período tinha como principal característica a despolitização e disputa em torno de interesses corporativos.

A impressão que tenho é que se manteve o projeto apenas para constar, porque tu terminar com uma iniciativa que formou tanta gente em Porto Alegre que serviu de base para ser copiado em outros municípios, que transformou pessoas, comunidades, cidade, tem que ter muito culhão, pois existia uma pressão social muito grande pela continuidade do projeto Mas que o projeto foi sucateado na mudança de governo foi que foi escanteado foi e se as pessoas conseguissem compreender um pouco mais que é mais fácil de conseguir asfalto, esgoto e comida e escola, quando tu tens mais gente que se formou por meio da descentralização da cultura, talvez não fosse simples assim sucatear o projeto de descentralização da cultura. Isso tem que deixar de ser projeto Em algum momento deixou de ser Mas hoje projeto ainda é muito vulnerável [...]. Entrevista a oficinanda de teatro no Vila Vicente Montegio e oficineira do Programa nos anos 2004 e 2006.

As conquistas em termos de discussão e ampliação da participação foram perdidas para as pautas dos interesses particulares. Os espaços do Programa foram progressivamente se despolitizando, perdendo seu valor em termos de conscientização e se voltando ao aspecto de produção, ou melhor dizendo, reprodução artística. As oficinas retomaram a concepção de espaços de lazer, distração e inclusão social.

Houve um enfraquecimento na participação e no interesse nas discussões. Com o orçamento reduzido, inicialmente tivemos que reduzir as nossas ações e enxugar nossa estrutura. Não tínhamos mais ativistas em cada área para discutir com as comissões... Existe um jogo de interesses no OP que impede que realmente cheguem até nós as demandas das regiões. Descentralizar é desconcentrar o poder. Se não fizermos isso, nosso propósito perde sua força [...]. Entrevista ao coordenador das oficinas desde 2001 e ativista da região da Restinga na Temática de Cultura do OP em 1994 
A eleição foi em 2004. Nessa época eu trabalhava no projeto Quando voltei em 2006 o projeto já estava diferente, diferente para pior. E daí depois de 2006, eu não me inscrevi mais, pois me decepcionei muito. Em 2006, fui oficineira no governo do Fogaça eu senti já que era pior Reduziu o tempo das oficinas e o cache, e principalmente, transformou as oficinas em um espaço de lazer, quer dizer, alienação [...]. Entrevista a uma oficinanda de teatro e depois oficineira do Programa nos anos 2004 e 2006.

Ou seja, diferentemente do objetivo inicial de formação política e cidadã, o Programa voltou-se para a formação artística. Com a desvalorização da concepção inicial o Descentralização se tornou um mercado de trabalho para artistas, uma fonte de renda esporádica e não mais um espaço de organização popular.

Tudo que foi conquistado nos primeiros anos do Projeto se perdeu As atividades do Descentralização foram se despolitizando até chegar ao que é hoje - um arremedo de ações culturais, sem pensar sobre, sem fazer uma reflexão sobre o porquê que estamos levando determinadas oficinas. Então questões do OP, que é um fórum legítimo, e se realmente não fosse um engodo seria um diferencial para a cidade, uma forma de democracia direta. Entrevista ao fundador e atuador do grupo de teatro de rua Ói Nóis Aqui Traveiz.

Não havia mais proposta política a ser supervisionada e o oficineiro torna-se responsável por estabelecer uma linha de trabalho e divulgar sua oficina nos bairros. Esta situação levou os grupos a buscarem outros canais e formas de atuação, autônomas em relação à Prefeitura. O coletivo Ói Nóis Aqui Traveiz iniciou oficinas de teatro de rua em diferentes regiões da cidade, mantendo a idéia de fomentar a discussão e formação política nas comunidades.

No bairro Humaitá, o trabalho do Ói Nóis inicia em 2003, ainda vinculado com o Descentralização da Cultura, e continua os dias de hoje, aí já de forma autônoma juntamente com o grupo que se formou a partir das oficinas, e que utiliza o ferrinho como sua sede, o grupo Trilho. Este trabalho, com o grupo Trilho, fomentou a criação de um centro cultural onde a principal atividade é o teatro. Era uma ação eminentemente política, porque tu abre um espaço que anteriormente não existia um espaço de discussão, de fomento de novos valores, de fomentar novas posturas e pensamentos A ação do descentralização sempre foi política. No momento que tu começa a trabalhar e desarmar isso num adolescente, isso é uma ação política No Humaitá desde então, a cultura passou estar sempre entre os primeiros colocados, fomentado pela participação na oficina. Porque funciona assim, estimulado, tu estimula o vizinho, aí estimula os parentes, aí decidem criar uma comissão de cultura. Entrevista ao fundador e atuador do grupo de teatro de rua Ói Nóis Aqui Traveiz.

Associações de Moradores das localidades - Vila do Industriários, 
Campo da Tuca, Vila do Bom Jesus, Vila do Tronco e Restinga, através da articulação com coletivos e artistas atuantes no Programa, passaram a oferecer oficinas artísticas independentes para as comunidades. Alguns coletivos, mesmo atuando de forma autônoma, não deixaram de organizar representações e lutar dentro da Temática de Cultura do OP. Em 2008, obtiveram o retorno das festas temáticas e a realização dos carnavais comunitários.

De um espaço com possibilidades de transformação social, o Descentralização da Cultura de Porto Alegre se transformou em um espaço de participação gerencial, no qual, as comunidades não participam das decisões políticas essenciais, e apenas assumem a realização dos eventos e festas idealizados pelo poder público. Ou seja, uma participação que em nada modifica as estruturas sociais do município e que não ais questiona a estrutura social.

\section{Considerações Finais}

O histórico do Programa DCP evidencia avanços e retrocessos em termos de democratização da gestão pública municipal e a participação política. A participação é um processo dinâmico e que precisa de atuação constante e revitalização da sociedade civil para conquistar, efetivamente, a radicalização democrática.

A experiência aqui estudada demonstrou que, a começar por uma disputa pela valorização de elementos sociais e políticos deste processo, foi possível redefinir, em alguns momentos, práticas no campo das políticas públicas culturais. Nestes períodos que, caracterizados pelo caráter das relações entre as administrações públicas e as comunidades e movimentos sociais envolvidos, puderam ser também associados a movimentações politicas nacionais e a inflexões nos discursos assumidos.

Foi possível igualmente reconstruir as efetivas influências das reivindicações e atuações dos grupos culturais e movimentos sociais na efetivação do Programa, desmentindo o discurso da decisão governamental. Por fim, parece importante assinalar o crescente conservadorismo no discurso das administrações públicas, com vistas a melhor entender o percurso sofrido pelas políticas públicas que se desvirtuam.

Se de um espaço de participação política, o Programa Descentralização se transformou em um espaço de participação gerencial, o processo de politização que ele possibilitou nos espaços que criou por um tempo, foram mais duradouros. 


\section{Referências}

Alencar, S. (1997), Atuadores da paixão. FUMPROARTE, Secretaria Municipal de Porto Alegre, Porto Alegre.

Amantino-De-Andrade, J.; Arenhart, A. J. (2005), "Participación social en el Sistema Único de Salud: una utopía por cumplirse en municipios de pequeño porte del Valle del Taquari”, en Misoczky, M. C.; Bordin, R. (Org.). Géstion Local de Salud, prácticas y reflexiones. DaCasa/OPAS, p. 37-56, Porto Alegre.

Baierle, S. G. (2000), “A explosão da experiência: emergência de um novo princípio ético-político nos movimentos populares urbanos em Porto Alegre”, en Alvarez, S. E.; Dagnino, E. et al. (org), Cultura e política nos movimentos sociais latino- americanos: novas leituras. UFMG, Belo Horizonte.

Bardin, L. (1977), Análise de conteúdo. 3. ed. Edições 70, Lisboa.

Boron, A. (2011), Pensamiento crítico y emancipación social. Programa Latinoamericano de Educación a Distancia, Centro Cultural de la Cooperación, Buenos Aires.

Brasil(2006), Ministério da Cultura. Programa Cultural para o Desenvolvimento do Brasil. MINC, Brasília.

Carvalho, C. A. (2009), “O Estado e a participação conquistada no campo das políticas públicas para a cultura no Brasil”, en Calaabre, L. (Org.). Políticas culturais: Reflexões e ações. 1 ed. Casa de Rui Barbosa, v. 1, p. 18-33, Rio de Janeiro.

Chaves, D. (2008), La política local de izquierda contra el pensamiento único. PLED (Programa Latinoamericano de Educación a Distancia en Ciencias Sociales), Buenos Aires.

Moraes, D. (2011), Notas sobre o imaginário social e hegemonia cultural. Gramsci e o Brasil, 2002. Disponível em: www.acessa.com/gramsci/ ?page=visualizar\&id=297. Acesso em: 17 de setembro de 2011.

Domingues, J. L. P.(2009), Programa Cultura Viva: políticas culturais para a emancipação das classes populares. 216 f. Dissertação (Mestrado em Políticas Públicas e Formação Humana) - Faculdade de Educação, UERJ, Rio de Janeiro.

Dorneles, P. (2001), Arte e Cidadania: Diálogos da experiência do Projeto Descentralização da Cultura da Administração Popular de Porto Alegre. Dissertação (Mestrado em Educação) - Pós Graduação em Educação, UFSC, Florianópolis. 
DSC/POA. (1994), Descentralização cultural: Administração popular de Porto Alegre. DSC, Porto Alegre. (documento interno) Fotocópia.

Freire, P. (2007), Ação cultural para a liberdade e outros escritos. 12. ed., Paz e Terra, São Paulo.

Gameiro, R. G.(2007), No Campo das Políticas Públicas Culturais em Pernambuco, os Caranguejos com cérebro se organizam para desorganizar. 2007. 210f. Dissertação (Mestrado em Administração) - UFPE, Pernambuco.

Gramsci, A. (1999), Cadernos do Cárcere. Edição de C. N. Coutinho com M. A. Nogueira e L. S. Henriques. Civilização Brasileira, Rio de Janeiro.

Marx, K. (2005), Critica da Filosofia do Direito de Hegel. Titulo Org. Zur Kritic der hegelschen Rechtsphilosophie. Trad. Rubens Enderle e Leonardo de Deus. Editora Boitempo, São Paulo.

Massa, C. D. (2004), Histórias Incompletas: As oficinas populares de teatro do Projeto de Descentralização da Cultura. Unidade Editorial da Secretaria Municipal de Cultura, Porto Alegre.

Motta, F. C. et al. (1987), Participação e participações: ensaios sobre autogestão. Babel Cultural, São Paulo.

Idem, (2003), Administração e participação: reflexões para a educação. v. 29, n. 22, p. 369 - 373, jul/dez, Educação e Pesquisa, São Paulo.

Nogueira, M. A. (2004), Um Estado para a Sociedade Civil: temas éticos e políticos da gestão democrática. 2. ed. Cortez, São Paulo.

Oliveira, J. (2010), Memória do Teatro de Rua em Porto Alegre. Editora Ueba, Porto Alegre.

Orofino, M. M. B. (2005), “É fazendo que se aprende: Um estudo sobre os oficineiros engajados nas políticas de cultura e assistência da Prefeitura Municipal de Porto Alegre”. Trabalho de Conclusão de Curso. Programa de pós Graduação em Ciências Sociais. PUC/RS, Porto Alegre.

Wood, E. M. W. (2003), Democracia contra capitalismo: a renovação do materialismo histórico. Boitempo, São Paulo.

SMC/POA, (1992), Informativo SMC. Prefeitura Municipal de Porto Alegre, Porto Alegre.

Spicer, A.; Böhm, S. (2013), “Moving Management: theorizing struggle against the hegemony of the management”, Organization Studies. (under review). Disponível em: http://sgboehm.googlepages.com/ movingmanagement14jul06.doc. Acesso em: 20 ago. 2013. 
Polis, Revista Latinoamericana, Volumen 12, $N^{\circ}$ 36, 2013

Tragtenberg, M. (1980), Administração, poder e ideologia. Moraes, São Paulo.

Viana, N. (2003), Estado, Democracia e Cidadania: a Dinâmica da Política Institucional no Capitalismo. Achiamé, Rio de Janeiro.

Recibido: 15.10.2013

Aceptado: 13.12.2013 